\title{
موقف ابن مالك عن الخلاف بين البصريين والكوفيين في كتاب ألفية ابن مالك
}

\section{Dede Rizal Munir ${ }^{1}$}

\section{DOI: https://doi.org/10.52593/klm.03.1.02}

\section{ملخص البحث}

كما هو المعروف أنَّ أحلدا من الكتب الدينية الني يبحث النحو هوكتاب ألفية ابن مالك. ألفية هي كتاب شعر في قواعد اللغة العربية، وبيمى الآخركتابا منظوما على بحر رجز، وكنلك المختصر ولكن يمتوي على معان عميق. جادير بالنكر، أنّ كتاب ألنية كثير من الخلاف العلماء النحوبين في شرحه، ومن الخلاف المشهور خحلافا بين العلماء الكوفيين والعلماء البصريين. وفقا بتحقيق البحث السابق تقرّر أغراض البحث هي لمعفة الأنظمة المختلف عليها البصريون والكوفيون في كتاب ألفية ابن مالك، لمعرفة المسائل المختلفة عليها البصريون والكوفيون في شرح الأنظمة في كتاب ألفية ابن مالك، لمعرفة موقف ابن مالك في المسائل المختلفة عليها البصريون والكوفيون في شرح الأنظمة في كتاب ألفية. طريقة البحث هي أنشطة استخدمها الباحث فى طلب البيانات الصحيحة المناسبة حتى يستغاد للفهم، والكشف، ومعالجة المشكلة في الفن من الفنون. هذا البحث معياري، ولنلك بستخدم الكاتب على الطريقة التحليلية في هذا البحث. ويستخدم الباحث الطريقة التحليلية كثير لأنما فعالة وفعالية، وأن يكون أساسا وكثير الفائدة. ونعرف أيضا من هذه الطريقة الإستنباط أو الفهم على المادة التى ألفها الصحغيون والكتاب (القرآن) أو المصادر الأخرى الصحيحة المركبة المناسبة. وبعد أداء دراسة على موقف /بن مالك بين البصريين والكوفيين في كتاب ألفية حصل الباحث على نتائج منها الأنظمة التي تحتوي على المسألة الخلافية بين البصرين والكوفيين في كتاب الفية وهي عشرون بابا.

${ }^{1}$ STAI DR. KH. EZ Muttaqien Purwakarta, derizalmunir@gmail.com. 


\title{
الكلمات المفتاحية: النحو، ألفية /بن مالك، الأنظمة
}

\begin{abstract}
SCIENCE NAHWU is one of the basic parts of grammar in Arabic to find out the position of the word in a sentence and the form of the last letter or vowel of a word. As we know, one of the books that discusses nahwu is the book of al-fiyah ibn malik. Al-fiyyah is a nadhom book of Arabic rules that has a Rajaz rhythm and summarizes the discussion by covering a deep meaning. Thus the purpose of this study is to find out the nadzhom that there are differences of opinion between the kuffah and bashrah scholars, to find out the problems of differences of opinion in the discussion of al-fiyyah. The research method uses two sources, namely primary and applied sources. The main source in this study is the thought of Nahwu ibn Malik in the book of al-Fiyyah. While the applied sources are related to the explanation of al-fiyyah such as the explanation of ibn aqil, al-makudi, ibn hamdun, al-khudhori and books related to the science of nahwu. Research results After conducting research on ibn malik's attitude between bashrah and kuffah scholars in the al-fiyyah book, some of which include differences of opinion between the bashrah and kuffah scholars in the al-fiyyah book contained in 20 chapters.
\end{abstract}

Keywords: nahwu, al-Fiyyah ibn Malik, nadhom.

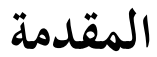

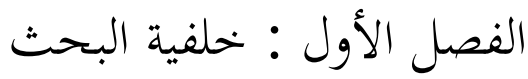

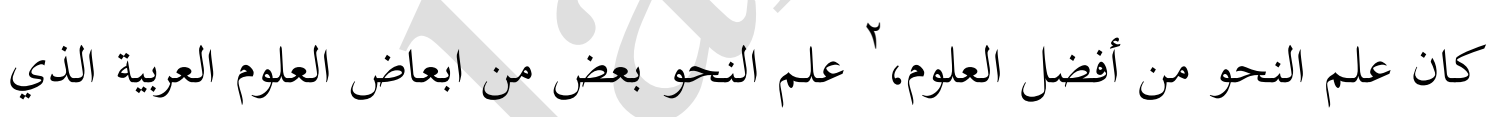
يهدف ان يتوصل بها الى عصمة اللسان والقلم عن الخطاء. وعلم النحو هو آخر على ما يقتضيه منهاج العرب في كلامهم من رفع ونصب وجزم. ورد إبراهيم مصطفى أن علم النحو هو علم الإعراب. واإلعراب أثر العامل، وهذه الفكرة

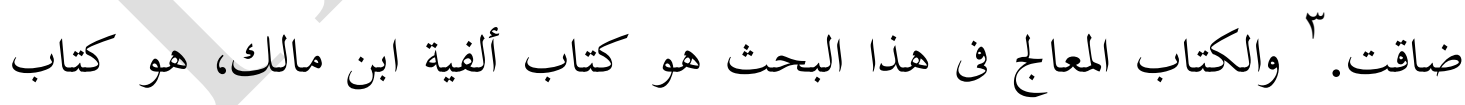
منظوم وعدده ألف بيت، هذاالكتاب يبحث عن علم النحو.

علم النحو هو علم بأصول يعرف بها أحوال أواخر الكلمة إعرابا وبناء وباعتبار كونه الة قانونية تعصم مراعتها اللسان عن الخطاء في المقال من حيث تأديته

\footnotetext{
2 Al Ajuri, Hasyiah Al Alamah Ibn Hamdun Ala Syarah Al Makudi Li Alfiyah Ibn Malik (Semarang: Toha Putra), p. 2.

3 Taufik Luthfi, 'NAZHARIYAH AL-'AMIL WA TADLAFUR AL-QARA'IN INDA TAMMAM HASAN', Arabiyat: Jurnal Pendidikan Bahasa Arab Dan Kebahasaaraban, 3.1 (2016), 98-121 (p. 100) <https://doi.org/http://dx.doi.org/10.15408/a.v3i1.2911>.
}

16 | Kalamuna: P-ISSN: 2655-4267, E-ISSN: 2745-6943 
اصل المعنى ؛ كما هو المعروف أنَّ أحدا من الكتب الدينية الذي يبحث النحو هو كتاب ألفية ابن مالك. ألفية هي كتاب شعر في قواعد اللغة العربية، ويسمى الآخر كتابا منظوما على بحر رجز، وكذلك المختصر ولكن يحتوي على معان عميق. جدير بالذكر، أنّ كتاب ألفية كثير من الخلاف العلماء النحويين في شرحه، ومن الخلاف المشهور خلافا بين العلماء الكوفيين والعلماء البصريين.

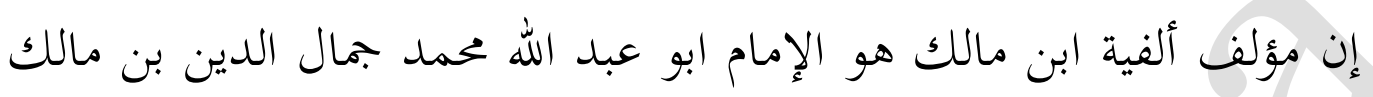

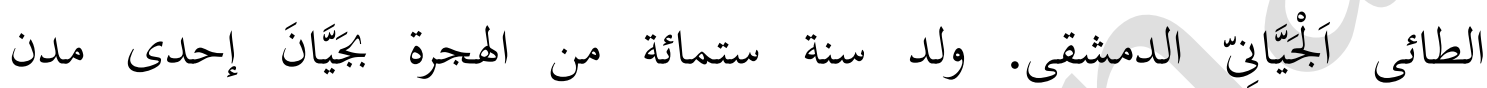
الأندلسى،ثم رحل الى دمشق واستزاد فيها من العلم، واقام بها مدة يصنف ويشتغل

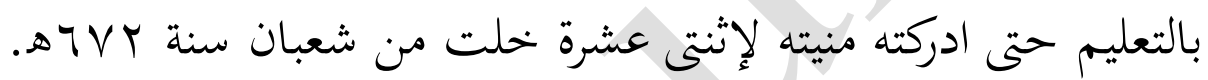
ومن خصائص كتاب ألفية هي يبين ابن مالك بطريقتين، الأولى، يأتي بألفاظ يسيرة جامعة لقواعد متعددة. الثاني، بالمثال الجحامع لشروط كثيرة جمعها غيره في ألفاظ

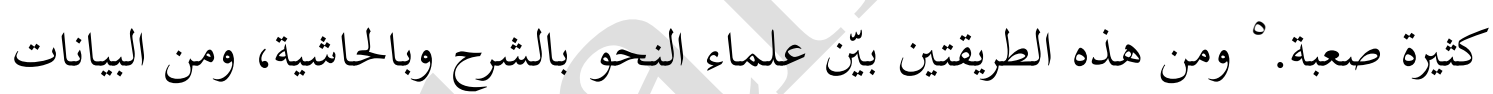
المشهورة في كتاب ألفية هي الخلاف بين علماء البصرة والكوفة في بيانه. وقد اختلف العلماء النحويون عن البحث في بيان الأنظمة، ومن اكبر علماء النحو هم البصريون والكوفيون. ولا تذكر البصرة الاّ تذكر معها الكوفة، فقدكان لمما

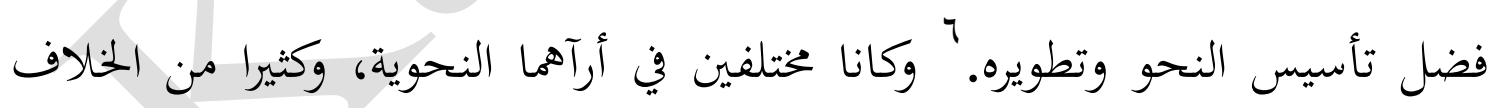
بين العلماء البصرة والكوفة في كتاب ألفية. وقد رأى عبد الله بن صالح الفوزان عن كتاب ألفية ابن مالك بقوله: (جاءت

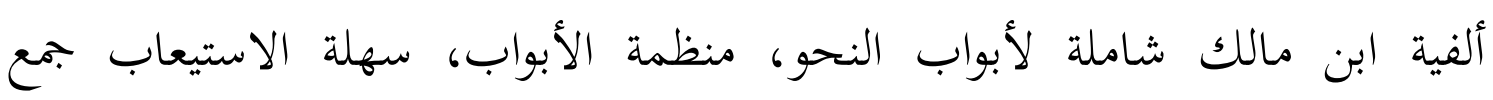

${ }^{4}$ Muhammad ibn hasan abdullah, Tashilul Masalik Fi Attarjamah Ibn Malik (Surabaya), p. 2.

${ }^{5} \mathrm{Al}$ Ajuri.

${ }^{6}$ al-Musthafâ Ghulâyainî and Syekh Mustofa, 'Jamiu Ad-Durus Al-Arabiyyah', Beirut: Daar Al-Fikr, 2006, p. 179. 
فيها الخلاصة ما أورده في الكافية). وزاد عبد الله بن صالح الفوزان رأيه في ذكر مميزات كتاب ألفية ابن مالك بقول بيان الأوجه الخلافية كقوله في باب التوكيد: وَإن

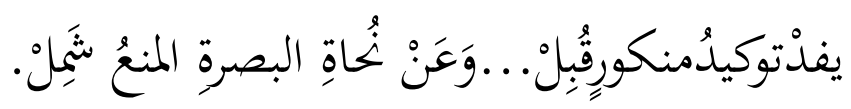
من المعلوم أنّ هذا النظم وجود الخلافية بين علماء البصرة والكوفة، والرأي المذكور ما ذهب إليه البصريون وهو ممنوع اسم النكرة محدودا، مثل يوم وليلة او غير محدود، مثل حين باستعمال التوكيد مطلقا، لأنّ أدوات التوكيد كلّها معارف. ولكن أجاز ذلك الكوفيون والأخفش قياساً معترفين بعدم السماع. مثلا: صمت شهرا كلّها. ومن هذا البيان رأى الباحث أن موقف ابن مالك يميل إلى مذهب الكوفيين. جدير بالذكر، أنّ كتاب ألفية كثير من الخلاف العلماء النحويين في شرحه، ومن الخلاف المشهور خلافا بين العلماء الكوفيين والعلماء البصريين. حتى يريد الباحث تحليلا على الموقف لابن مالك في الموضوع: موقف ابن مالك عن الحنلاف بين البصريين والكوفيين في كتاب ألفية. من البيان السابق، تبدو أن المشكاتلات في

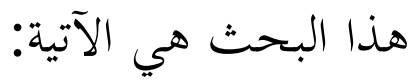
ا ـ ماهي الأنظمة المختلف عليها البصريون والكوفيون في كتاب ألفية ابن مالك؟ Y. ماهي المسائل المختلفة عليها البصريون والكوفيون في شرح الأنظمة في كتاب ألفية ابن مالك؟ r ـ كيف موقف ابن مالك في المسائل المختلفة عليها البصريون والكوفيون في شرح الأنظمة في كتاب ألفية ابن مالك؟

$$
\text { أغراض البحث وفوائده }
$$

\footnotetext{
${ }^{7}$ Abdurohman Ali Sulaiman, Syarah Wa Attahqiq Taudih Al Maqosid Wal Masalik Bi Syarah Al Fiyah Ibn Malik Lil Muradi, 1st edn (Al Qohiroh: Darul Fikri Al Arabi), p. 10.

8 Muhammad ibn hasan abdullah.
}

18 | Kalamuna: P-ISSN: 2655-4267, E-ISSN: 2745-6943 


\section{وفقا بتحقيق البحث السابق تقرّر أغراض البحث كما يلي:}

I ـ معرفة الأنظمة المختلف عليها البصريون والكوفيون في كتاب ألفية ابن

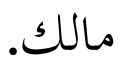

r ـ معرفة المسائل المختلفة عليها البصريون والكوفيون في شرح الأنظمة في كتاب ألفية ابن مالك.

ץ. معرفة موقف ابن مالك في المسائل المختلفة عليها البصريون والكوفيون

$$
\text { في شرح الأنظمة في كتاب ألفية. }
$$

\section{فوائد البحث}

يتمنى الباحث أن لهذا البحث فوائد كثيرة، إما للباحث نفسه وإما للقارئ عامة. وذلك إما نظريا وإما تطبيقيا. فنظريا، ترجى الفوائد الآتية تأتي من هذالبحث:

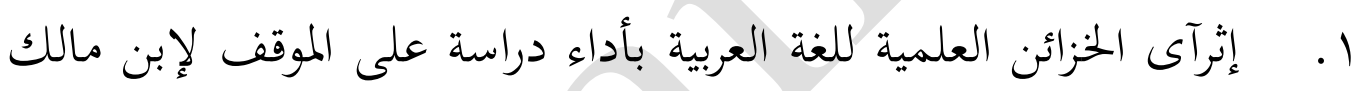
عن الخلاف بين البصريين والكوفيين. r. ت ت تويسع المحال الدراسي لقسم اللغة العربية. "ا م أن تكون مادة لتطوير بحث اللغة العربية في المستقبل.

$$
\text { الفوائد التطبيقي }
$$

بعد أن تؤدي دراسة على الموقف لابن مالك عن الخلاف بين البصريين والكوفيين، يرجي على مدرس اللغة ألة يأتي بما يصح ويرجع في تصنيف المواد الدراسية من ناحية تحديد نوعية وكمية ومقيات المادة التي يجب ليجب أن تدرس، وكذلك تسهيل الطالب فهم القواعد النحوية في التعلم والتعليم.

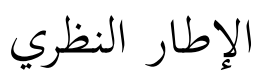


Kalamuna, Vol. 3. No. 1, Januari 2022. 15 - 31

كان أهم الفروق الأساسية بين المذهبين هو أن مذهب البصرة رأت أهم غرض وضع قواعد عامة للغة تلتمزها وتريد أن تسير عليها في دقة وحزم. وإذا كانت اللغات دائما لا تلزم القواعد العامة بل فيها مسائل لا يمكن أن بتحري على القاعدة وخاصة اللغة العربية التي هي لغة قبائل متعددة تختلف فيما بينهما إختلافا كبيرا. فقد أراد البصريون تمشيا مع غرضهم أن يهدروا الشواذ. فإذا ثبتت صحتها قالوا إها تحفظ ولا يقاس عليها.

وإذا رأوا( إن )تنصب الاسم وترفع الحبر غالبا. ثم رأوها في بعض المواضع لاتسير هذا السير مع الوثوق بصحت ماورد نهو( إن هذان لساحران) الزموا الناس باتباع الأغلب. مع محاولة تأويل ماورد تأويلا يتفق قواعدهم ولو بنوع تكلف.

فالبصريوف يفضلوف القياس ويؤمنون بسلطانه ويجرون عليه ويهدرون ما عداه. وإذا رأوا لغتين: لغة تسير مع القياس ولغة لاتسير عليه فضلوا التي لاتسير عليه

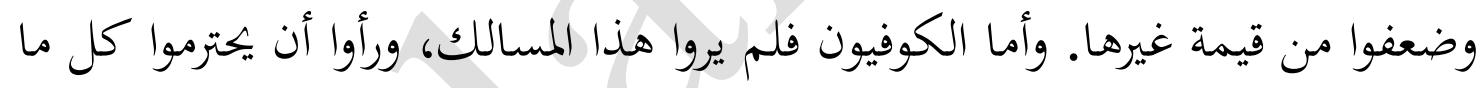
جاء عن العرب ويجيزوا للناس أن يستعملوا استعمالهم ولو كان الإستعمال لاينطبق على القواعد العامة بل يجعلون هذا الشذوذ أساسا لوضع قاعدة عامة. قال الأندلوسي : (الكوفيون لوسمعوا بيتا واحدا فيه جواز شيئ خالف للأصول جعله أصلا وبوّبوا عليه).

فهم أكثر بتحويزا للوجوه المختلفة في المسائل المختلفة. فإذا سمعوا مثلا (ياليت عدة حول كله رجب) وضعوا لذلك قاعدة مع أنه شاذ لأنه وصف الحول وهو نكرة بكله وهو معرفة. وأجازوا أن تقول: صمت شهرا كله وتجدت ليلة كلها. أما البصريون فيردون عليهم أولا، إن هذا البيت لم يعرف قائله وثانيا: لو صاح لكان شاذ القياس عليه. 


\section{منهجية البحث}

كان موضوع الذي اتخذه الباحث في هذا البحث هو " التفكير النحوي لابن مالك (دراسة تحليلية على موقف ابن مالك عن الخلاف بين علماء البصريين

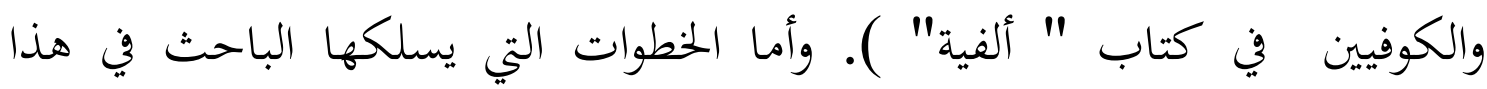

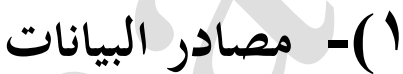

استخدم الباحث في هذا البحث نوعين من مصادر البيانات، مصدر أساسي

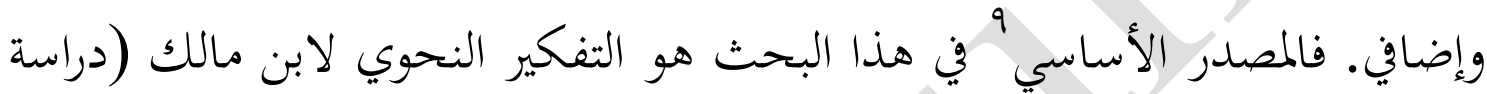
تحليلية على موقف ابن مالك عن الخلاف بين علماء البصريين والكوفيين في كتاب

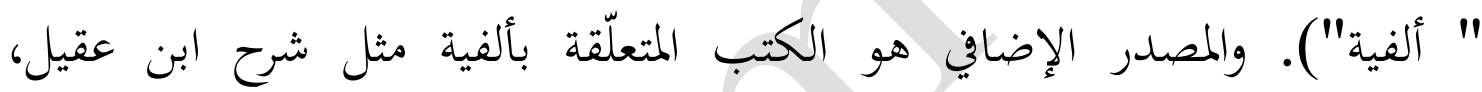
المكودي، حاشية العلاّمة ابن حمدون، الخضري وغير ذلك، والكتب الموب المتعلقة بعلم النحو مطابقة بموضوع.

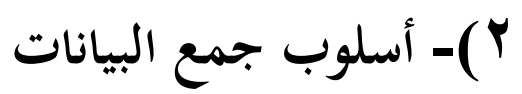

$$
\begin{aligned}
& \text { يحتاج في جمع البيانات إلى خطوتين وهما: } \\
& \text { أ. دراسة الكتب }
\end{aligned}
$$

وهي بحث مكتبي يتعلق بالبيانات النظرية. ويستخدم هذا الأسلوب

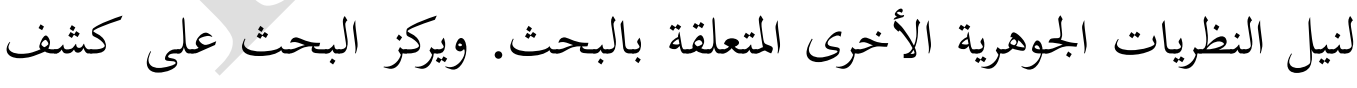

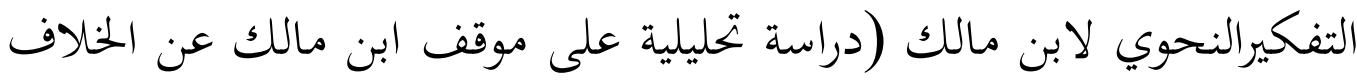

$$
\text { ب. بين علماء البصريين والكوفيين في كتاب " ألفية" ). }
$$

${ }_{9}^{9}$ Hadari Nawawi dan Mimi Martini, Penelitian Terapan (Yogyakarta: Gajah Mada University Press, 1996). 
وذلك بجمع الأنظمة في كتاب " ألفية "التي تكون الخلاف بين

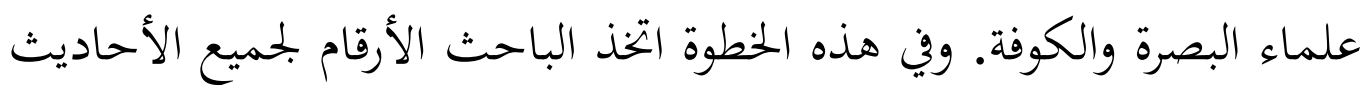

$$
\text { ب) البحموعة لتسهيل البحث. }
$$

بعد أن يجمع جميع البيانات و تصنيفها بنظام، فالخطوة تليهاهي تحليل

البيانات نوعية باستخذام الطريقة التالية :

$$
\text { أ. طريقة البحث }
$$

طريقة البحث هي أنشطة استخدمها الباحث في طلب البيانات

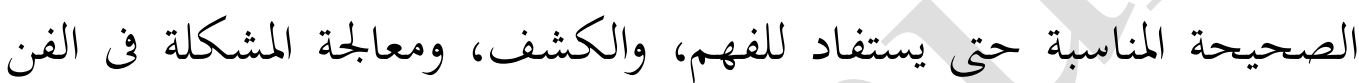

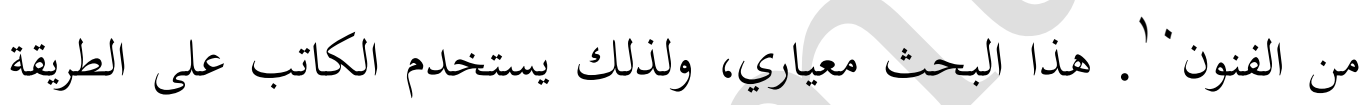
التحليلية في هذا البحث. يستخدم الباحثون طريقة التحليلية كثيرا لأفا فعالة

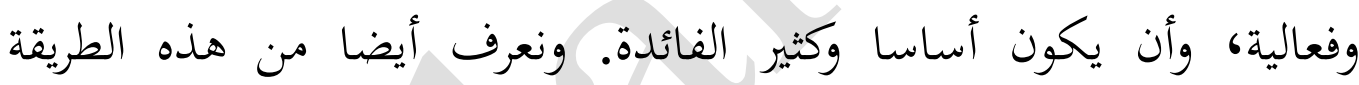

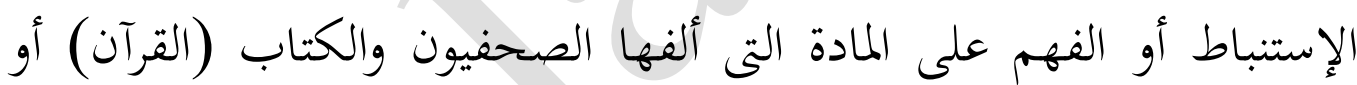

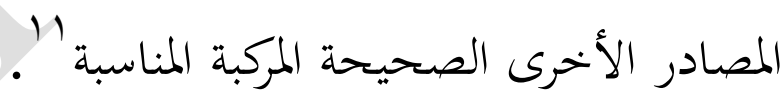

$$
\begin{aligned}
& \text { ب. تحليل البيانات } \\
& \text { يجتاج في تحليل البيانات إلى ثلاثة خطوات وهي: } \\
& \text { 1- مطابقة البيانات }
\end{aligned}
$$

المراد بها تفريق البيانات وتصنيفها المتعلقة بالأنظمة النحوية في كتاب

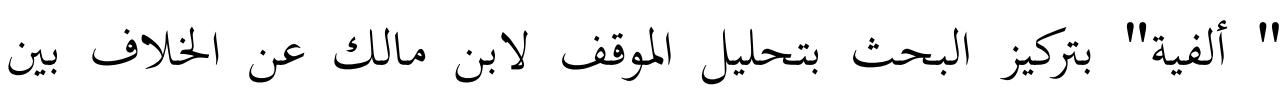

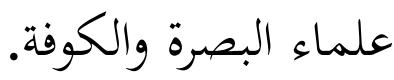

10 Yaya S. dan Tedi P, Metodologi Penelitian Pendidikan (Bandung: Sahifa), p. 84.

11 Imam Suprayogo, Metodologi Sosial Agama (Bandung: Remaja Rosda Karya, 2001), p. 154.

22 | Kalamuna: P-ISSN: 2655-4267, E-ISSN: 2745-6943 
موقف ابن مالك عن الخلاف... (Dede Rizal Munir)

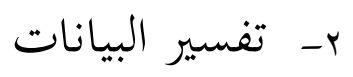

وهي عملية توصيف كشف التفكير النحوي لابن مالك بتحليل موقف ابن مالك عن الخلاف بين علماء البصريين والكوفيين في كتاب

$$
\text { "ألفية" موتعن }
$$

r- كشف أوجه التشابه عن الخلاف بين علماء البصرة والكوفة في كتاب

$$
\text { ع- الاستنتاج }
$$

وهو تقرير الجوانب العامة الظاهرة من عملية البحث حسب تحقيق

مشكلاته المقررة. والاستنتاج من هذا البحث يرام للإجحابة عن مشكلات

البحث وهي : معرفة الموقف لابن مالك عن الخلاف بين البصريين

$$
\text { والكوفيين في كتاب ألفية. }
$$

\begin{tabular}{|c|c|c|}
\hline موقف ابن مالك & المسائل & أنظمة ألفية ابن مالك \\
\hline يميل & 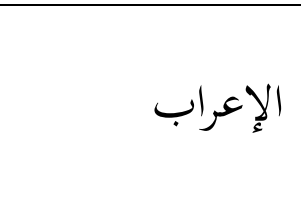 & 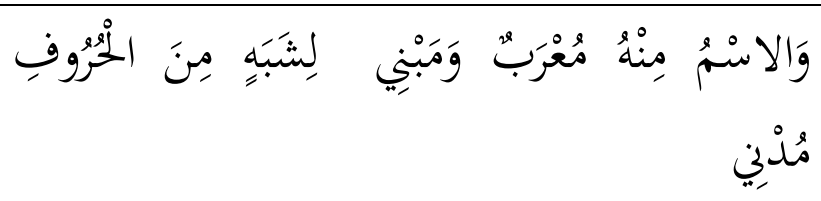 \\
\hline يميل الى مذهب & 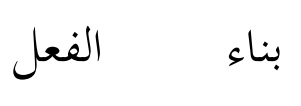 & 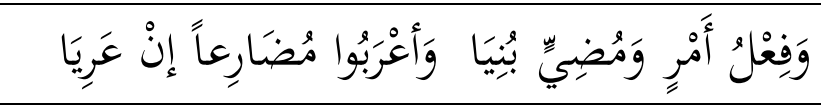 \\
\hline البصريين & ومعربه & 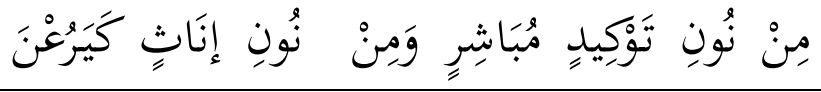 \\
\hline
\end{tabular}

كان الموقف الإمام ابن مالك عن المسائل المختلفة عليها الكوفيون والبصريون يبدو فيما يلي:

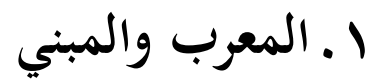


Kalamuna, Vol. 3. No. 1, Januari 2022. 15 - 31

\begin{tabular}{|c|c|c|}
\hline & & مَنْ فُنْنْ \\
\hline \multicolumn{3}{|r|}{ r. العلم } \\
\hline موقف ابن مالك & | المسائل & أنظمة ألفية ابن مالك \\
\hline البصريين & 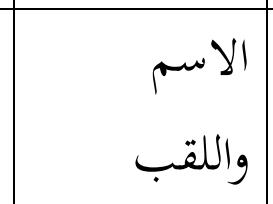 & رَرِفْن \\
\hline \multicolumn{3}{|r|}{ r. اسم الاشارة } \\
\hline موقف ابن مالك & | المسائل & أنظمة ألفية ابن مالك \\
\hline | يميل & | ذا (الالف) & 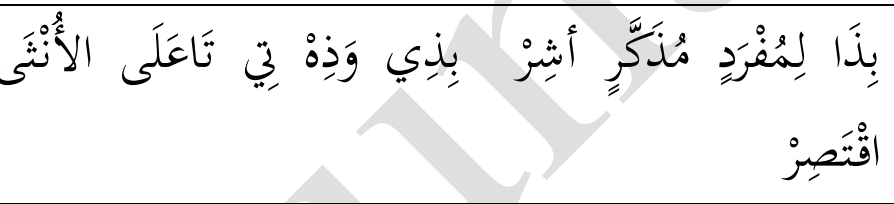 \\
\hline
\end{tabular}

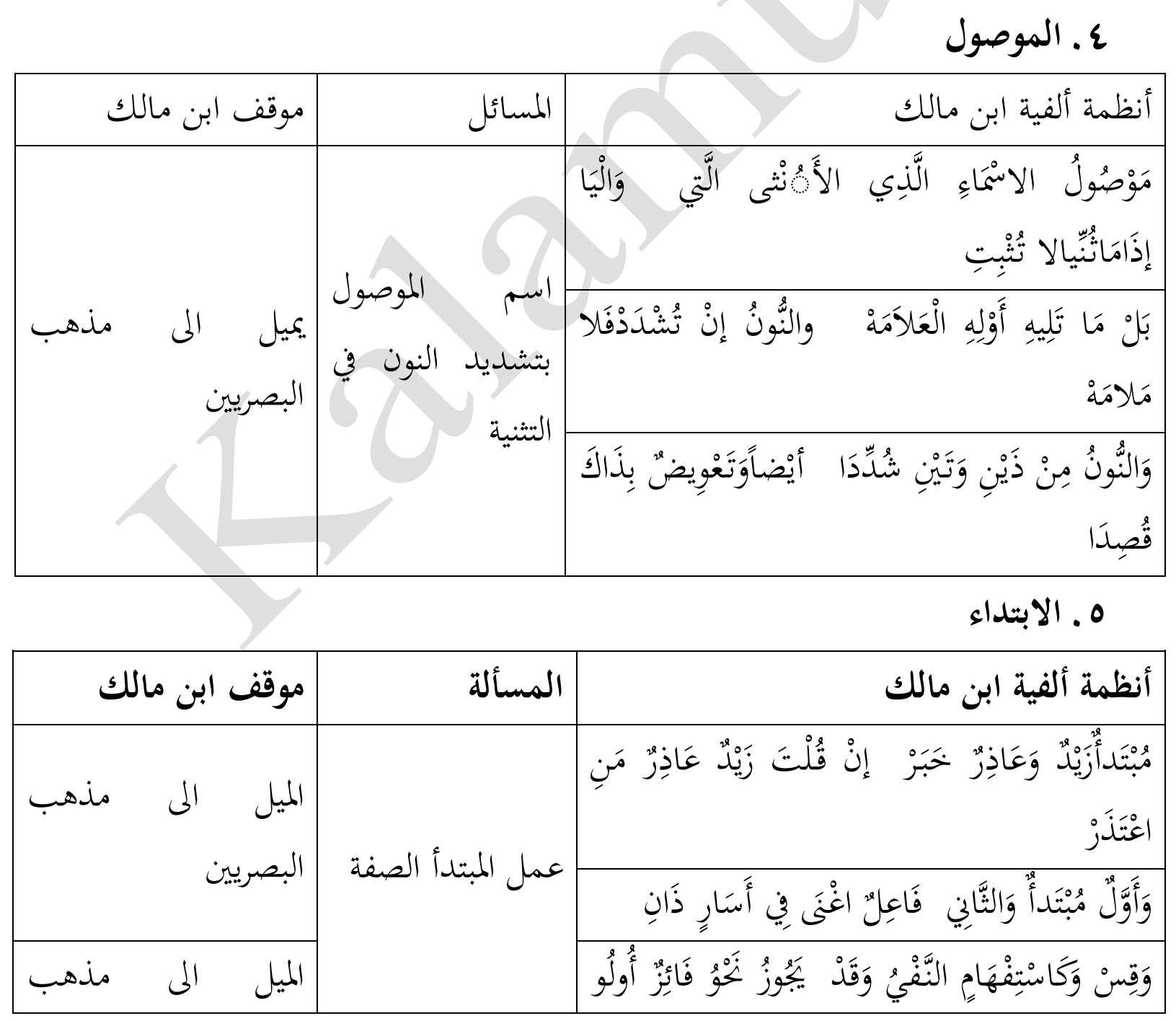


موقف ابن مالك عن الخلاف (Dede Rizal Munir)

\begin{tabular}{|c|c|c|}
\hline الكوفين & & الرَّشَدْ \\
\hline البصريين & رفع المبتدأ والخبر & 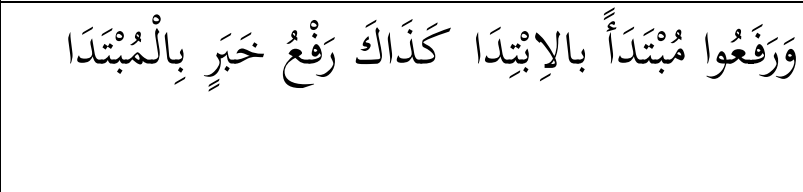 \\
\hline البعريل & الخبر جامد ومشتق & 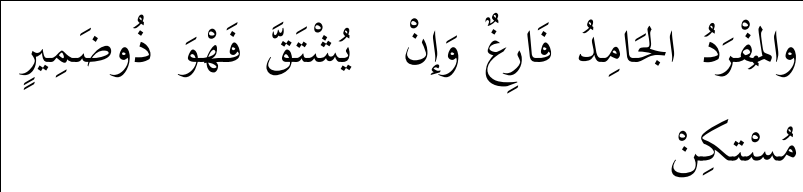 \\
\hline البصيل & وإبراز & 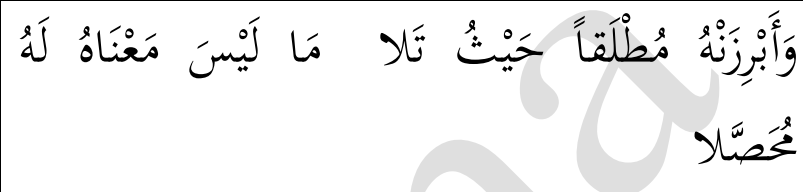 \\
\hline التسامح بين البصريين & ظوف & 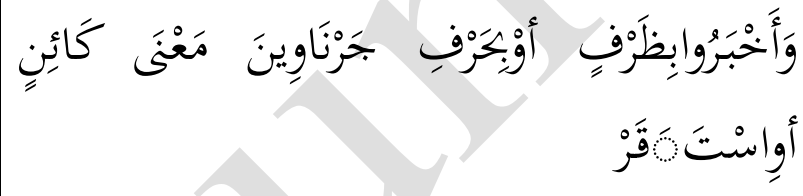 \\
\hline التسامح بين البصريين & خبر اسم الذات & فَأَخْنَr \\
\hline البصريين والكوفيين بين مذهب & تقديع الخبر & 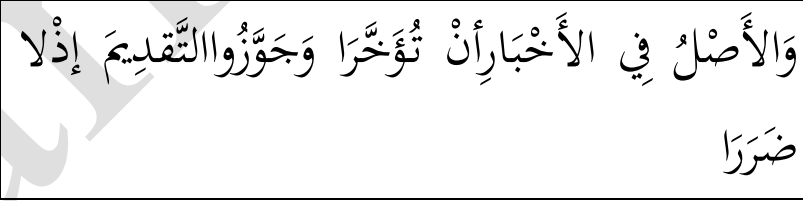 \\
\hline
\end{tabular}

7 ـ كان وأخواتها

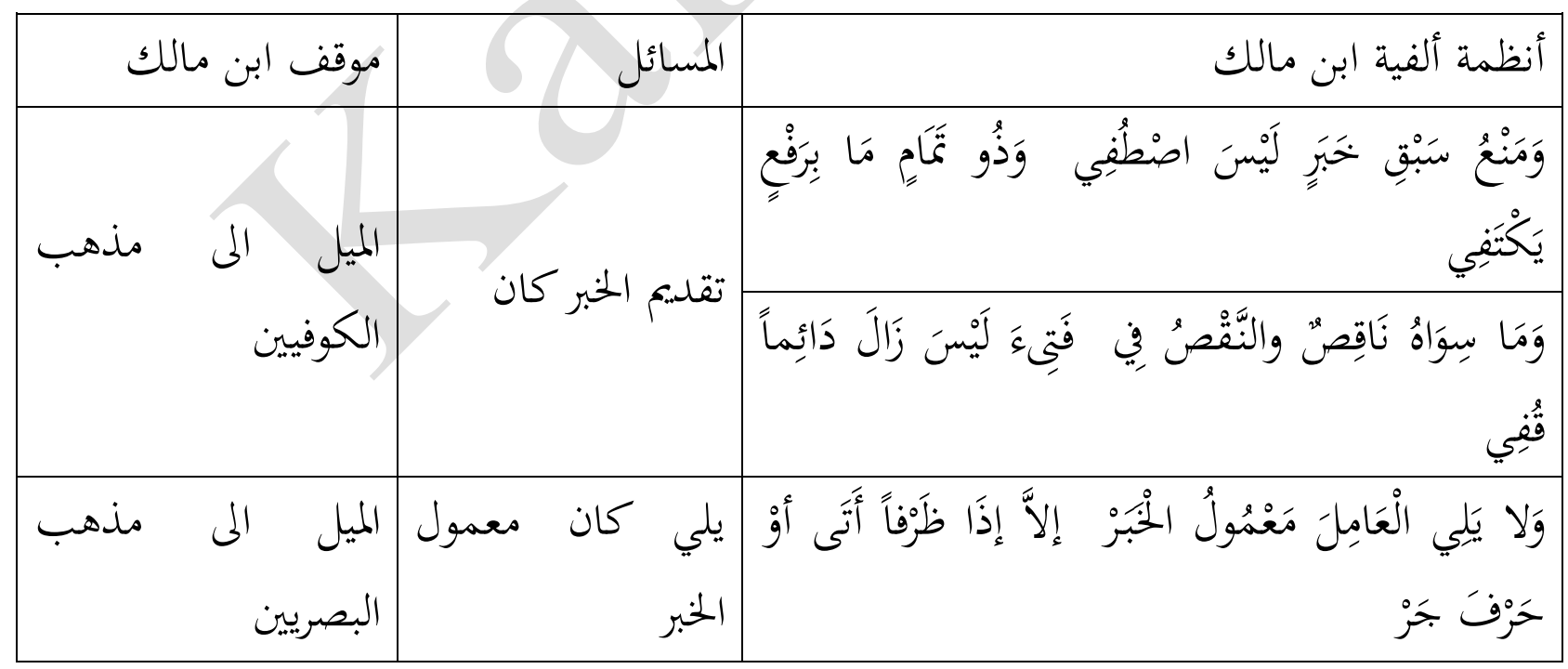

V . فصل في ما ولا ولات وإنّ المشتهات بليس تجر

أنظمة ألفية ابن مالك 
Kalamuna, Vol. 3. No. 1, Januari 2022. 15 - 31

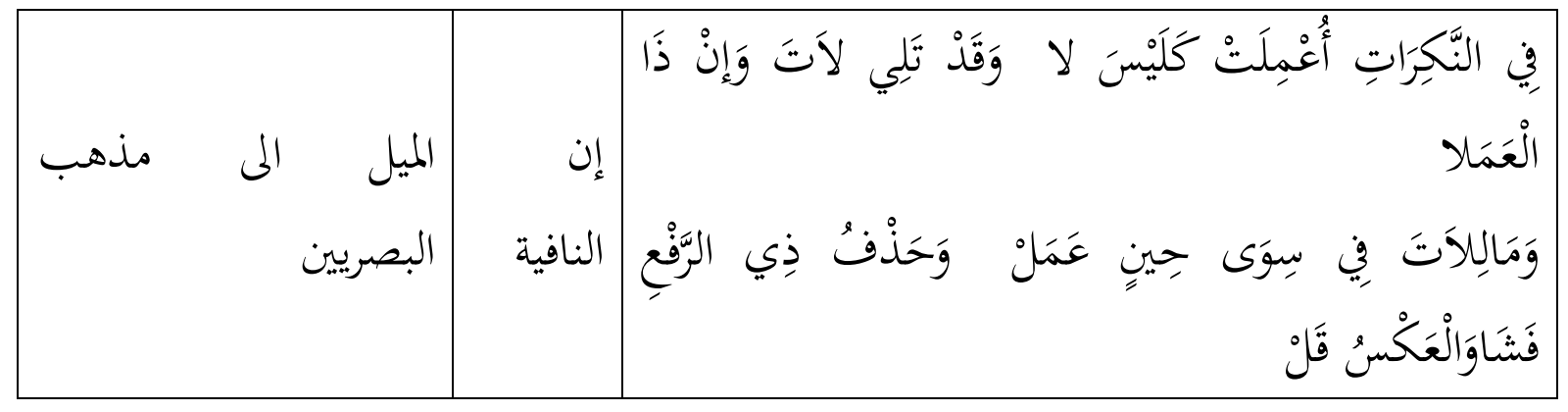

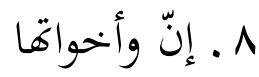

\begin{tabular}{|c|c|c|}
\hline موقف ابن مالك & المسائل & أنظمة ألفية ابن مالك \\
\hline الموفيين & الجزأين $\quad$ علة & 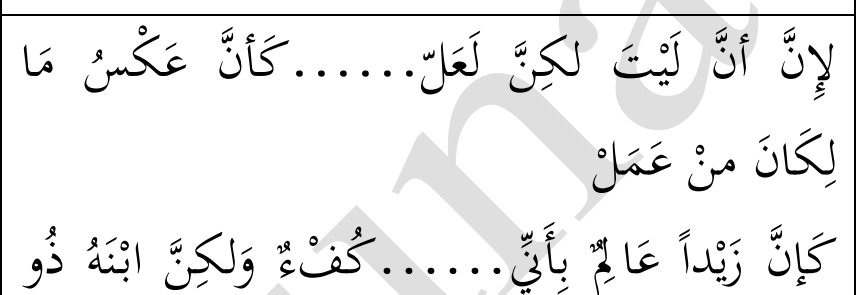 \\
\hline
\end{tabular}

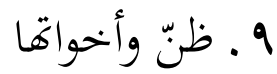

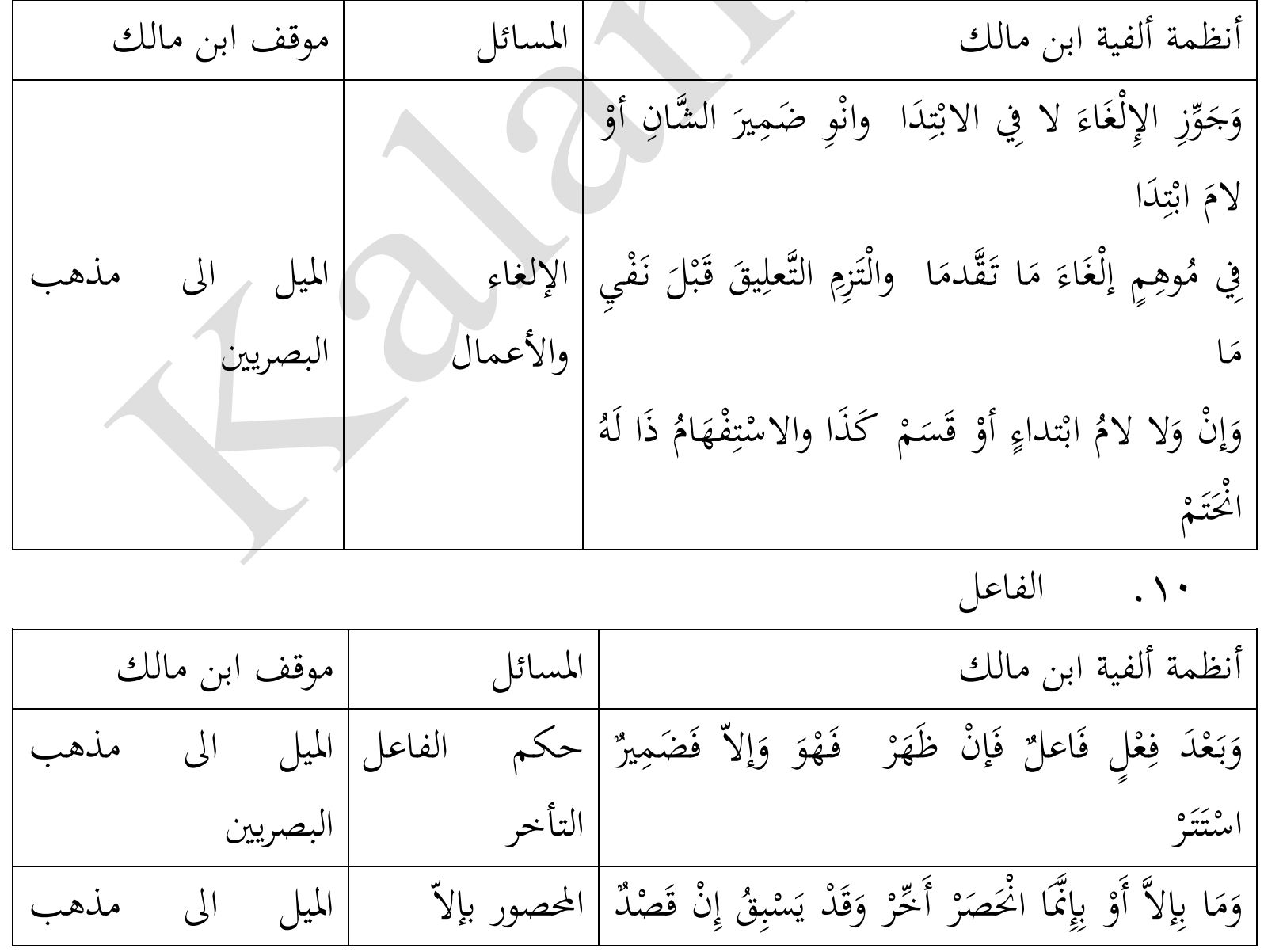


موقف ابن مالك عن الخلاف ... (Dede Rizal Munir)

\begin{tabular}{|c|c|c|}
\hline البصريين & & ظَهَهْ \\
\hline الميل & المفعول المتقدم & 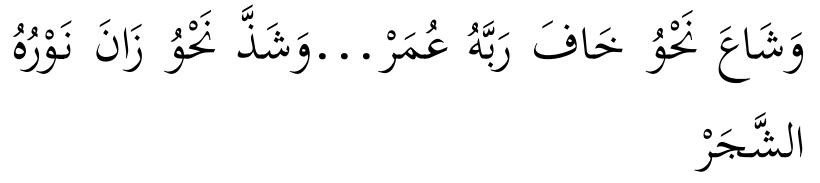 \\
\hline
\end{tabular}

\begin{tabular}{|c|c|c|}
\hline موقف ابن مالك & المسائل & أنظمة ألفية ابن مالك \\
\hline الميل البصريين مذهب & به إقامة مفعول & 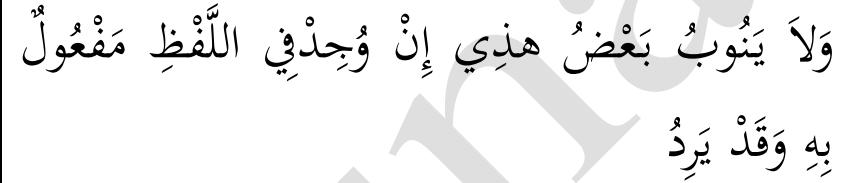 \\
\hline
\end{tabular}

\begin{tabular}{|c|c|c|}
\hline موقف ابن مالك & 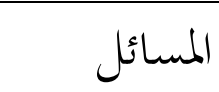 & لمة ألفية ابن مالك ك ل \\
\hline الميل & من & 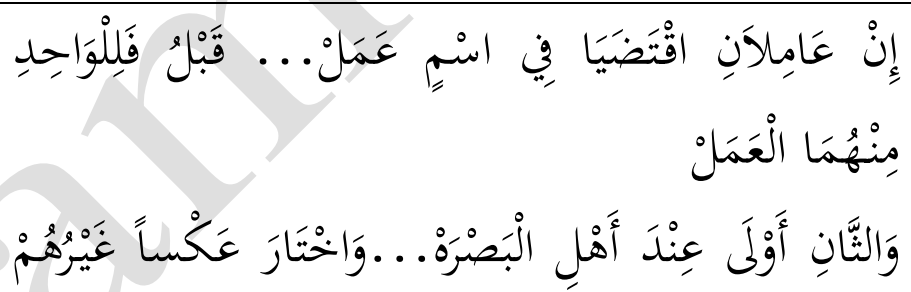 \\
\hline الى مذهب & احدالعاملين & 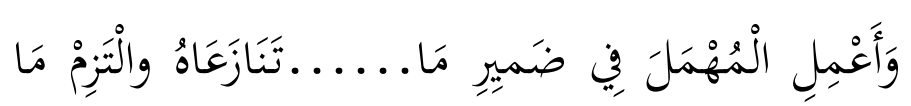 \\
\hline الميل & مفعول & 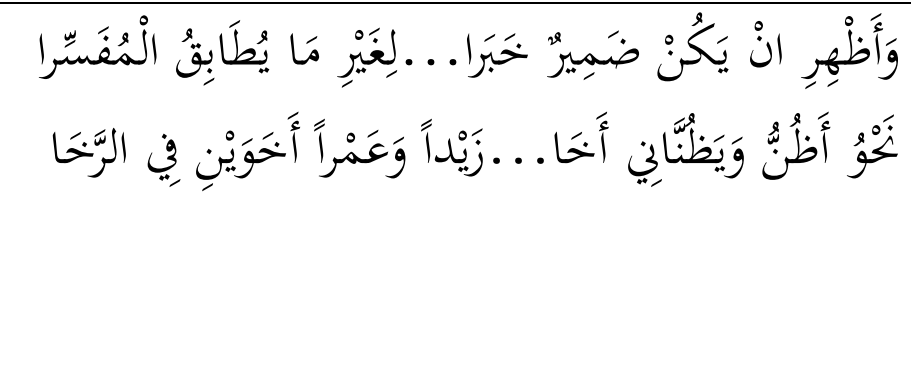 \\
\hline
\end{tabular}

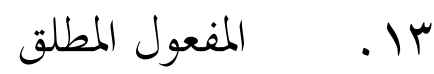


Kalamuna, Vol. 3. No. 1, Januari 2022. 15 - 31

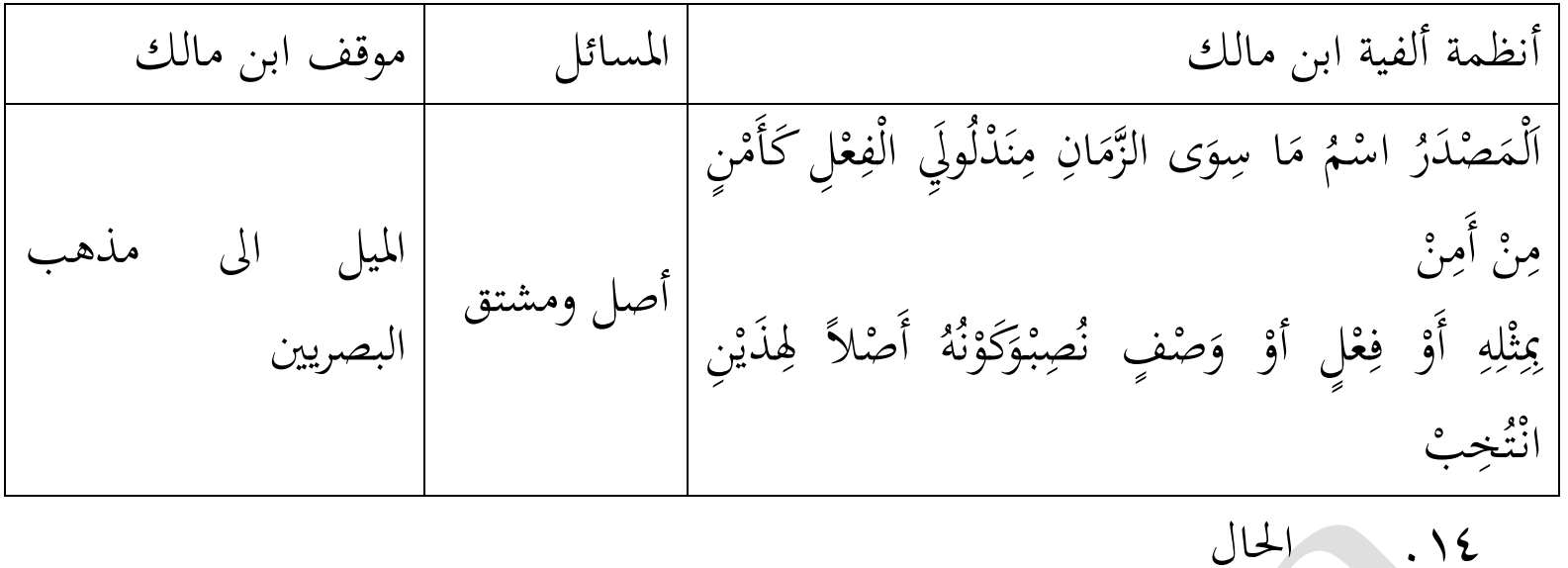

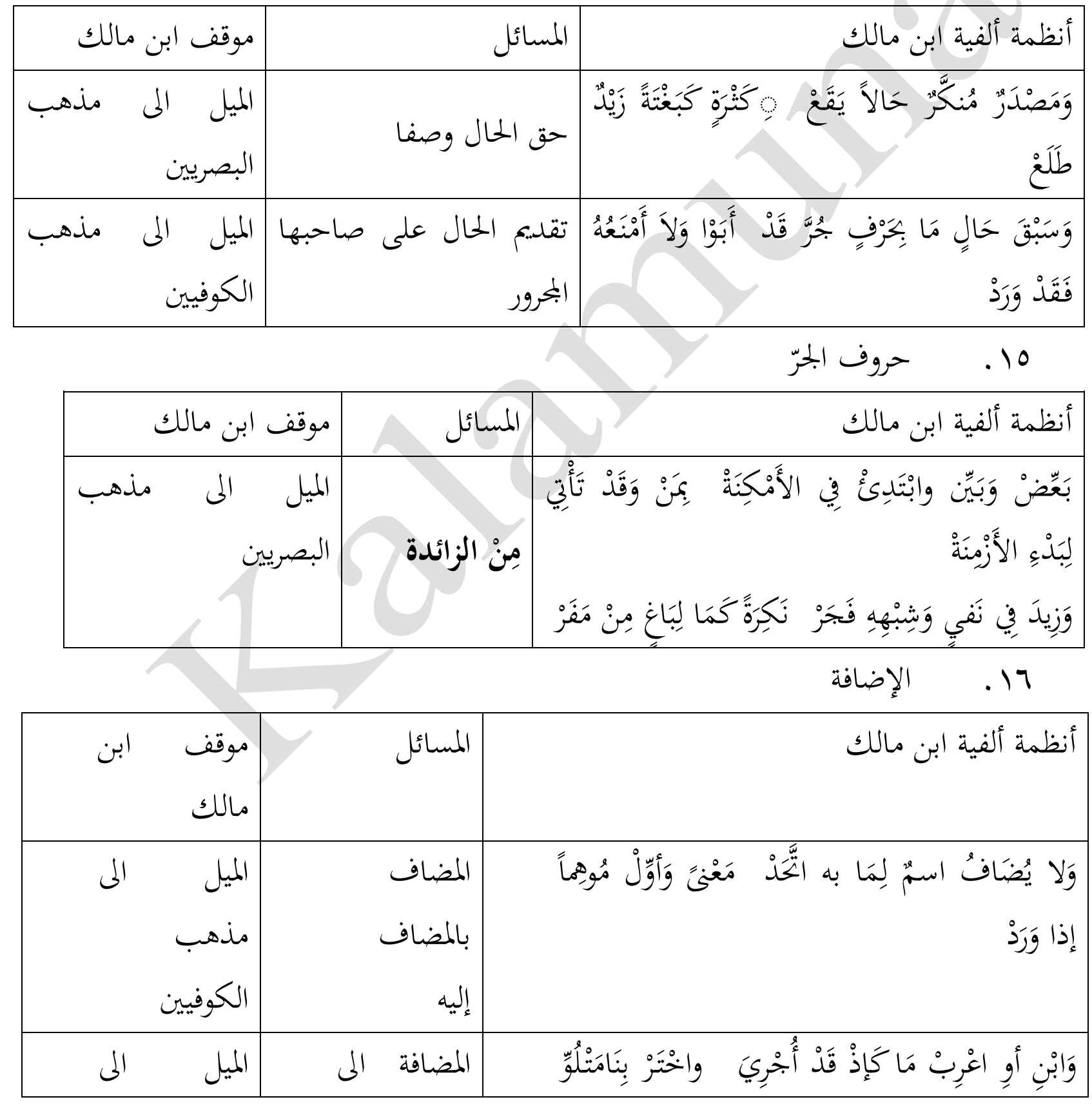


موقف ابن مالك عن الخلاف ... (Dede Rizal Munir)

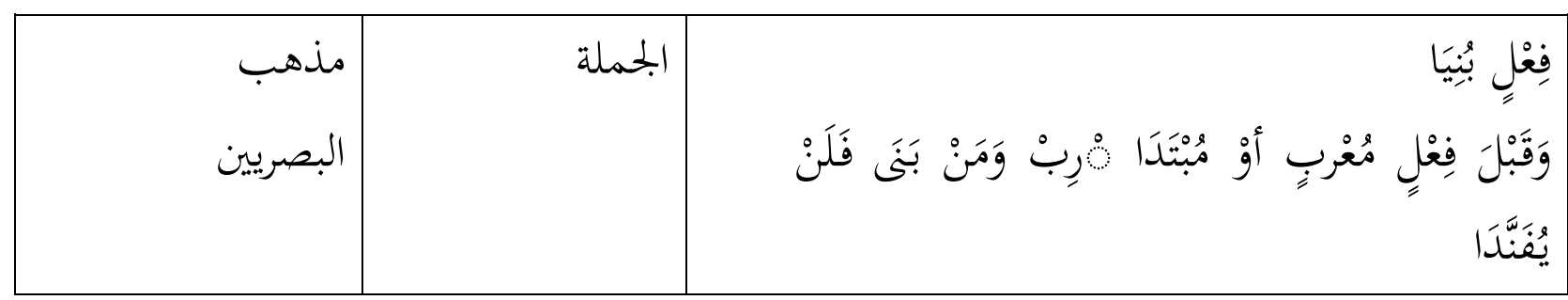

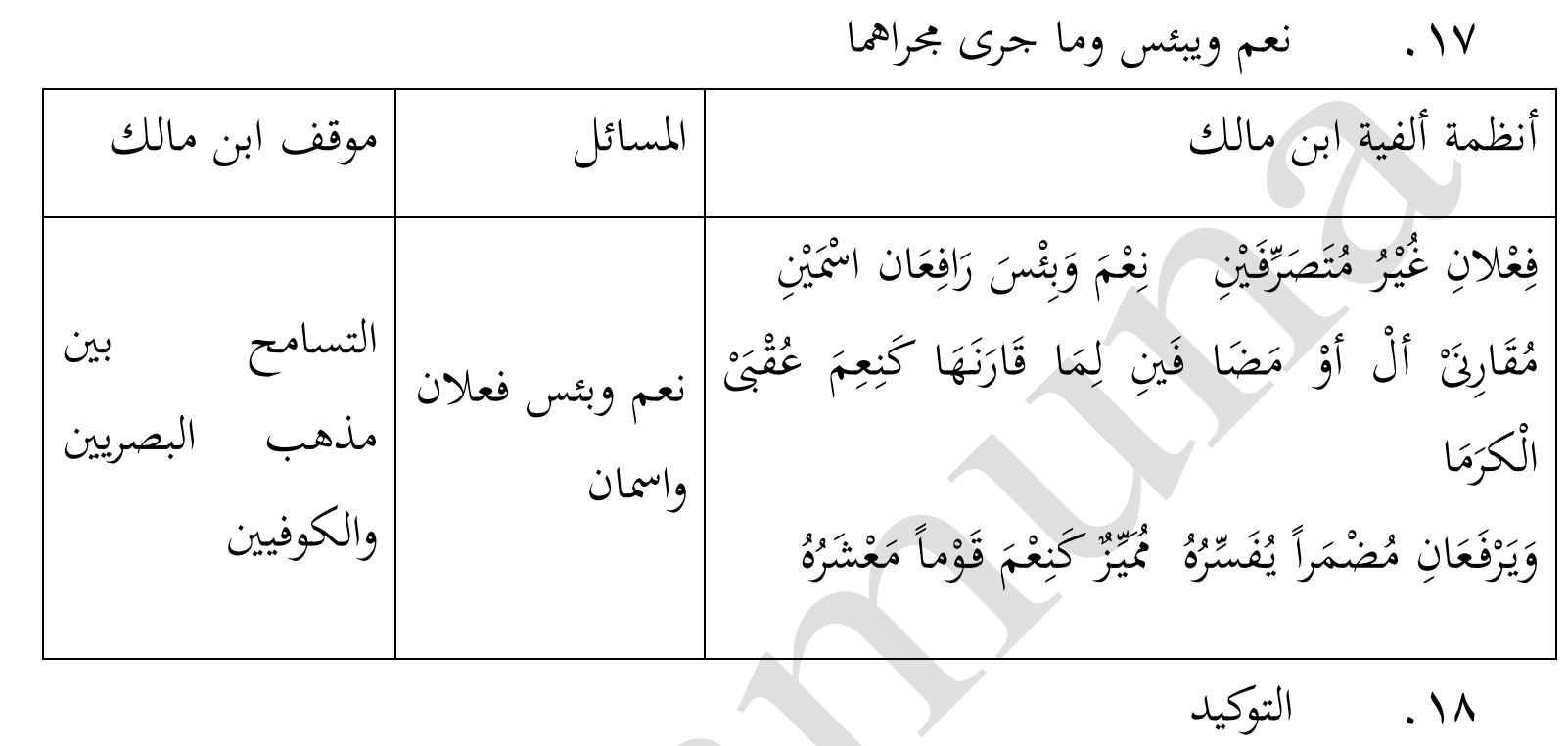

\begin{tabular}{|c|c|c|}
\hline موقف ابن مالك & & أنظمة ألفية ابن مالك \\
\hline الميل الى مذهب & توكيد النكرة & 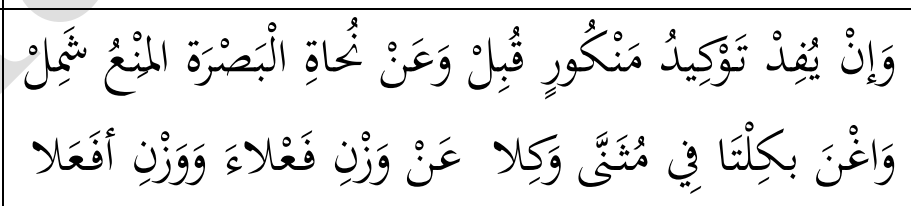 \\
\hline
\end{tabular}

\begin{tabular}{|c|c|c|}
\hline موقف ابن مالك & المسائل & أنظمة ألفية ابن مالك \\
\hline | الميل الى مذهب & المنصرف ل من للصرف & 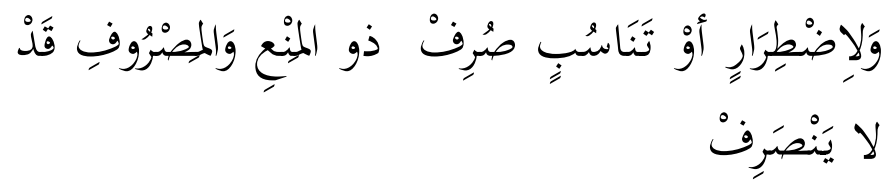 \\
\hline & & المقصور والممدود \\
\hline موقف ابن مالك & المسائل & أنظمة ألفية ابن مالك \\
\hline
\end{tabular}


Kalamuna, Vol. 3. No. 1, Januari 2022. 15 - 31

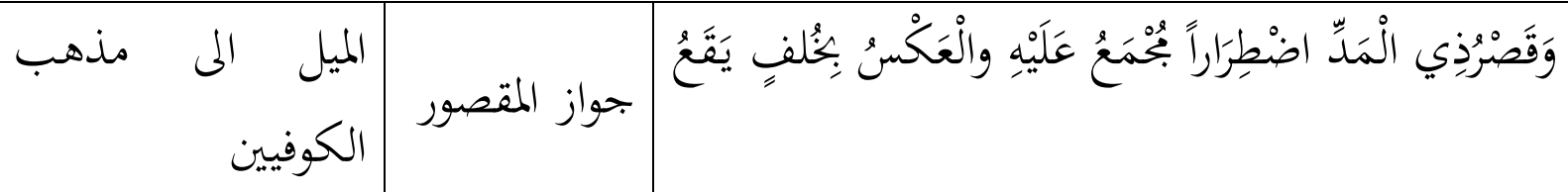

وبعد أداء دراسة على موقف ابن مالك بين البصريين والكوفيين في كتاب ألفية

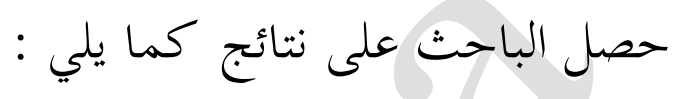

1 الأنظمة التي تحتوي على المسألة الخلافية بين البصريين والكوفيين في كتاب الفية

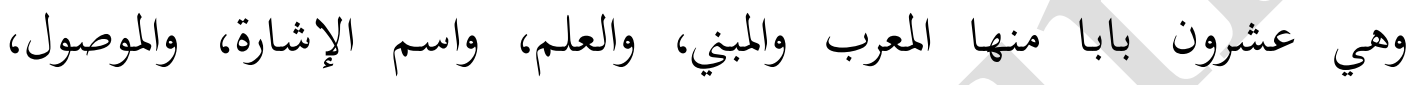
والإبتداء، وكان وأخواتما، وفصل في ما ولا ولات وإنّ المشبهات بليس، وإنّ إنّا وأخواتها، وظنّ وأخواتما، والفاعل، والنائب عن الفاعل، والتنازع في العمل، واتهال والمفعول المطلق، والحال، وحروف الجار، والإضافة، ونعم وبئس وما جرى بحراهما،

$$
\text { والتوكيد، ومالا ينصرف، والمقصور والممدود. }
$$

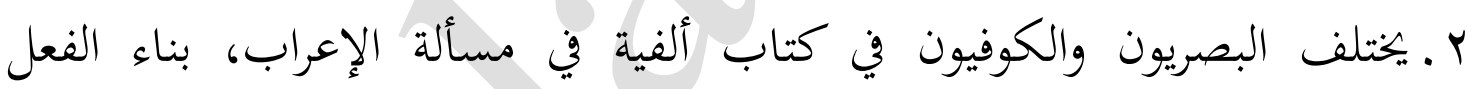
ومعربه، والاسم واللقب، وذا (الالف)، واسم الموصول بتشديد النون في الثنية،

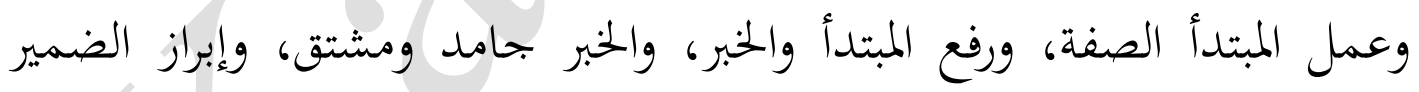
وإخفائه، وكون الخبر ظرفاوبكرورا، وخبر اسم الذات، وتقديم الخبر، وتقديم الخبر

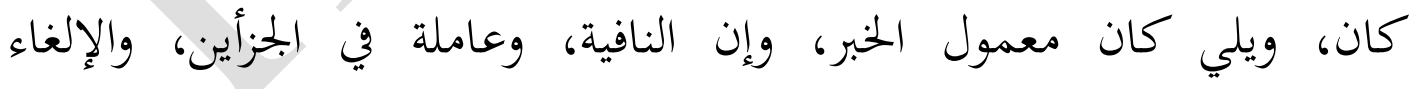

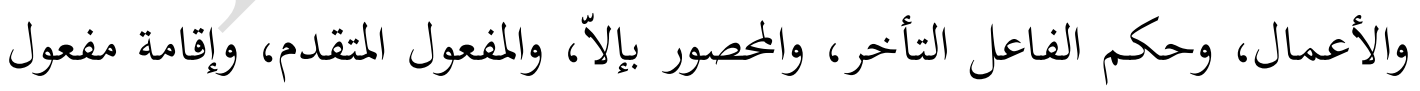
به مقام الفاعل، والأولى من العاملين، واعملت احدالعاملين وأهمل الآخر، ومفعول الفعل المهمل ظاهرا، وأصل ومشتق، وتقديم الحال على صاحبها البحرور، ومينْ الزائدة، والمضاف بالمضاف إليه، والمضافة الى الجملة، ونعم وبئس فعلان واسمان، وتوكيد النكرة المحدودة، والمنصرف من الصرف للضرورة، وجواز المقصور. 


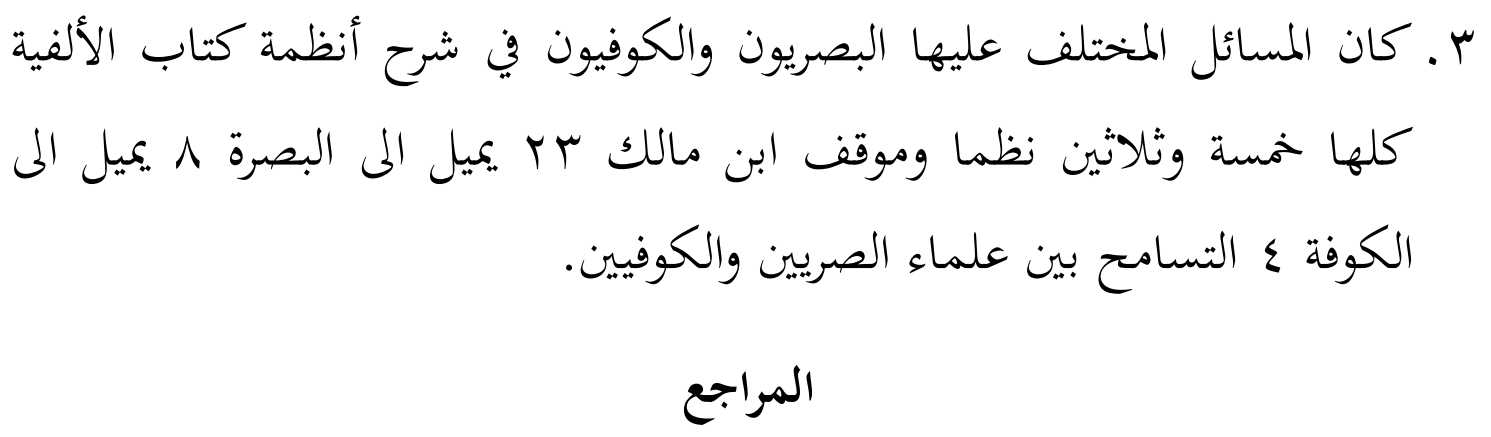

Abdurohman Ali Sulaiman, Syarah Wa Attahqiq Taudih Al Maqosid Wal Masalik Bi Syarah Al Fiyah Ibn Malik Lil Muradi, 1st edn (Al Qohiroh: Darul Fikri Al Arabi) Al Ajuri, Hasyiah Al Alamah Ibn Hamdun Ala Syarah Al Makudi Li Alfiyah Ibn Malik (Semarang: Toha Putra)

Ghulâyainî, al-Musthafâ, and Syekh Mustofa, 'Jamiu Ad-Durus Al-Arabiyyah', Beirut: Daar Al-Fikr, 2006

Imam Suprayogo, Metodologi Sosial Agama (Bandung: Remaja Rosda Karya, 2001) Luthfi, Taufik, 'NAZHARIYAH AL-'AMIL WA TADLAFUR AL-QARA'IN INDA TAMMAM HASAN', Arabiyat: Jurnal Pendidikan Bahasa Arab Dan Kebahasaaraban, 3.1 (2016), 98-121

<https://doi.org/http://dx.doi.org/10.15408/a.v3i1.2911>

Martini, Hadari Nawawi dan Mimi, Penelitian Terapan (Yogyakarta: Gajah Mada University Press, 1996)

Muhammad ibn hasan abdullah, Tashilul Masalik Fi Attarjamah Ibn Malik (Surabaya) P, Yaya S. dan Tedi, Metodologi Penelitian Pendidikan (Bandung: Sahifa) 